\title{
Identification of Resistant Sources for Alternaria Blight of Pigeonpea (Cajanus cajan L. Millsp)
}

\author{
Utkarsh Singh Rathore $^{1 *}$, S.K. Singh ${ }^{2}$ and Sandeep Kumar ${ }^{1}$ \\ ${ }^{1}$ Crop Protection Division, Indian Institute of Pulses Research, Kanpur-208024, India \\ ${ }^{2}$ Narendra Dev University of Agriculture and Technology, Kumarganj, Faizabad, India \\ *Corresponding author
}

\begin{tabular}{|l|}
\hline Ke y w o r d s \\
Alternaria tenuissima, \\
$\begin{array}{l}\text { Varietal screening, Host } \\
\text { Plant Resistance, Disease } \\
\text { inhibition, Resistant lines }\end{array}$ \\
\hline Article Info \\
\hline Accepted: \\
26 March 2018 \\
Available Online: \\
10 April 2018 \\
\hline
\end{tabular}

\section{A B S T R A C T}

Pigeonpea (Cajanus cajan L. Millsp) is the most important grain legume grown in India. The crop is affected at various stages of the crop. Among the biotic stress stresses, Alternaria blight, caused by Alternaria tenussima is one of the most important foliar diseases of pigeonpea. Management of this disease through chemicals pesticides is not feasible and it affects the human, animal and ultimate causes the environmental pollution. Hence, considering host plant resistance (HPR) is one of the most important tools in managing this disease and reducing the yield losses of pigeonpea caused by Alternaria tenuissima. One hundred six genotypes of pigeonpea were obtained from the Department of Genetics and Plant Breeding, N.D. University of Agriculture and Technology (Kumarganj), Faizabad (U.P.) and screened at University Research farm for their reaction to Alternaria tenuissima under natural and artificial inoculated conditions by spraying inoculums (15-20 conidia/microscopic field). The genotypes were screened by 1-9 scale disease rating scale. Out of 106 genotypes, seven genotypes viz. Path 402, Path 407, NDA14-4, NDA14-15, NDA-14-16, NDA-14-29 and NDA-14-36 were found resistant, 33 genotypes were found moderately resistant, 53 genotypes were found moderately susceptible and 13 genotypes were found susceptible to Alternaria blight. The most susceptible variety Bahar showed 100 percent blighting. Resistant lines can by exploited in resistant breeding programme.

\section{Highlights}

Out of 106 genotypes, 7 genotypes of pigeon pea showed resistance against Alternaria blight

Percent leaf infection i.e., 10-30\% were categorized as moderately resistant genotypes (33)

Bahar showed 100\% susceptibility

\section{Introduction}

Pulses play a major role in nutritional security for the people taking cereal based diet. Beside their dietary value and nitrogen fixing ability, pulses also play an important role in sustaining intensive agriculture by improving physical, chemical and biological properties of soil and are considered excellent crop for diversification of cereal based cropping system. 
Pigeonpea pods are consumed as green vegetable in many countries. Dry seeds of pigeonpea are consumed as split dal and also used as ration for milking cattle. Its straw is also palatable and green leaves may be used as fodder. Sticks of pigeonpea are used for various purposes such as thatch and basket making etc. Recently its use as a fodder crop has increased. Seed contains approx., 20-22\% protein. They are rich in iron, iodine, and essential amino acids like Lycine, Cystine and Arginine. Pigeonpea being a leguminous plant is capable of fixing atmospheric nitrogen and thereby restore lot of nitrogen in the soil.

India is the largest producer and consumer of pulses in the world and also key player with 25 per cent share in the global basket from an area about 33 per cent (Ali, 2007). Total pulses produced in India was $18.45 \mathrm{mt}$, covering area about $24.00 \mathrm{~m}$ ha with average productivity of $699 \mathrm{~kg} / \mathrm{hectare}$ (Anonymous, 2013).

Among the pulses, pigeonpea (Cajanus cajan (L.) Millsp.) which is also known as arhar, tur, redgram, cangopea and gandul holds an important position in Indian subcontinent. Besides India, it is also grown in South East Asia, Africa and America. South Asia contributed about $95 \%$ production of pigeonpea and $90 \%$ of which produced by India. It is now widely grown in Indian subcontinent. In India, it is grown on $3.81 \mathrm{~m}$ ha area, producing $3.02 \mathrm{mt}$ from with productivity of $806 \mathrm{~kg} / \mathrm{ha}$ (Anonymous 2013). The crop is mainly grown in Andhra Pradesh, Bihar, Uttar Pradesh, Karnataka, Gujarat, Madhya Pradesh, Maharashtra, Orissa and Tamilnadu. In Uttar Pradesh it is grown on $0.31 \mathrm{~m}$ ha area producing $0.37 \mathrm{mt}$, with an average yield of $1199 \mathrm{~kg} / \mathrm{ha}$ (Anonymous, 2013).

The yield of pigeonpea $(699 \mathrm{~kg} / \mathrm{ha})$ is much lower than potential yield of 2000 to 2500 $\mathrm{kg} / \mathrm{ha}$ with improved varieties. The poor yield of pigeonpea is mainly due to biotic stress like diseases and insect pests.

The crop is infected by 210 pathogens ( 83 fungi, 4 bacteria, 19 viruses and mycoplasma and 104 nematodes) reported from 58 countries. The maximum number has been reported from India with 98 pathogens (Nene et al., 1996) but only few of them like wilt, sterility mosaic, phytophthora blight and alternaria blight are major and destructive diseases.

Alternaria blight caused by Alternaria tenuissima is one of the most widespread and destructive foliar diseases of Rabi pigeonpea. The disease was first described by Pavgi and Singh in 1971 followed by Kannaiyan and Nene in 1977-1980 crop season on September planted pigeonpea cultivar (Bahar and Basant) in northern Indian staes of Uttar Pradesh and Bihar (Mehta and Sinha, 1982; Narula, 1983 and Venkateswarlu et al., 1981). The fungus causing leaf spot of pigeonpea observed by Kannaiyan and Nene in year 1997 at ICRISAT, Hyderabad. The disease appeared in epiphyotic form on September planted pigeonpea during February, 1980 in Muzzaffarpur district of Bihar and also in 1981 in Varanasi and other areas of eastern Uttar Pradesh (Kannaiyan and Nene, 1977).

The incidence varied from $18.0 \%$ to $37.5 \%$ in different locations of Central Uttar Pradesh (Kushwaha et al., 2010). Hence, for minimizing the losses caused by Alternaria blight need inexpensive and environmentally safe management practices.

It was, therefore considered desirable to identify resistant varieties and disease management through botanicals with the following objectives:

Symptamology of the disease, 
Isolation of the Alternaria tenuissima from pigeonpea and its pathogenicity,

Identification of pigeonpea genotype(s) resistant to A.tenuissima.

The present studies were carried out in the laboratory and glass house of the Department of Plant Pathology, Narendra Deva University of Agriculture and Technology, Narendra Nagar (Kumarganj), Faizabad (U.P.). The details of materials used, experimental procedures followed and techniques adopted are given as under:

\section{Symptomology}

The symptoms of the Alternaria blight disease were carefully observed and recorded at seedling and adult plant stage of the crop on farmers field and experiment station.

\section{Collection of Alternaria blight infected pigeonpea plants}

Pigeonpea plants showing characteristic symptoms of Alternaria blight collected from G.P.B. research farm of Narendra Deva University of Agriculture and Technology, Narendra Nagar (Kumarganj), Faizabad (U.P.). Infected parts of pigeonpea plants were cut from leaves and stems and kept in rough dry envelopes especially meant for the purpose. Each envelope was marked clearly mentioning location, variety, date of collection etc. and were brought to the laboratory. The samples were dried for 24 hours in shade in order to remove excess surface moisture. After drying, the samples were kept in Refrigerator in paper envelop and maintained at 6 to $8{ }^{\circ} \mathrm{C}$ temperature for isolation and further studies.

\section{Sterilization of metal and glass wares}

Metallic objects like blade, scissor, forceps, inoculation needle, cork borer etc. were sterilized by dipping in the spirit and heating on flame to red hot before inoculation. Laminar flow was sterilized with formaline and ultra violet lamp before use. Spirit was used as general disinfectant of hand. Glass ware, such as Petri plate, culture tubes, funnel, glass rods, beakers and flasks etc. were cleaned in chromic acid (potassium dichromate $60 \mathrm{~g}$, concentrated sulphuric acid 60 $\mathrm{ml}$ and water $100 \mathrm{ml}$ ) followed by washing in running water. Dry glass wares were sterilized at $160{ }^{\circ} \mathrm{C}$ for 2 hours in an electric hot air oven.

\section{Preparation of culture media}

Potato-Dextrose-Agar medium was used for isolation and maintaing of pure culture of the Alternaria blight pathogen. The ingredients of the Potato Dextrose Agar medium used during the course of investigation are given below.

\section{Potato Dextrose Agar medium (PDA medium)}

Potato Dextrose Agar medium having following composition was prepared by following method described by Jonhston and Booth (1983).

Peeled potato: $200.00 \mathrm{~g}$

Dextrose: $20.00 \mathrm{~g}$

Agar: $20.00 \mathrm{~g}$

Distilled water: $1000.00 \mathrm{ml}$

The peeled potatoes were cut in $12 \mathrm{~mm}$ cubes. Two hundred grams of potato cubes were rinsed in water and boiled for 20 minutes in $500 \mathrm{ml}$ water. Potato broth was filtered through cheese cloth and kept in measuring cylinder.

Agar was melted in $500 \mathrm{ml}$ of water by heating and added to potato broth. Dextrose was added in it. The final volume was made up to $1000 \mathrm{ml}$ by adding distilled water. The 
pH was adjusted to 7.0. The PDA was poured in test tube for preparation of PDA slant and also in flask. Then these were sterilized at 15 p.s.i for 20 minutes in an autoclave.

\section{Method of isolation}

The diseased leaves of pigeonpea showing distinct characteristics of Alternaria blight disease, were selected for isolation of the pathogen.

The selected leaves were washed with fresh sterilized water in order to remove the dust particles and surface contaminants. The washed diseased parts were cut into small bits, with some healthy portions, with the help of sterilized scalpel and forceps. The cut pieces were surface sterilized with 0.1 per cent mercuric chloride solution under aseptic condition inside a laminar flow and washed thoroughly 3 to 4 times with sterilized water to remove the trace of mercuric chloride.

Excess moisture was removed by placing these in the fold of sterilized blotting papers.

The pieces, thus sterilized, were transferred in Petri plates with the help of sterilized needles. Petri plates used in the experiment were previously sterilized and poured with Potato Dextrose Agar Medium. The medium was previously autoclaved at 15 p.s.i for 20 minutes.

Three to four pieces of diseased leaves of pigeonpea were placed in Petri plates of equal distances from each other. Petri plates were properly marked with glass marking pencil indicating date of isolation the Petri plate were then transfered at $28 \pm 2^{\circ} \mathrm{C}$ temperature for 7 days in an incubator. As soon as the mycelial growth was visible around there pieces the hyphal tips from the advancing mycelium were cut and transfered into the culture slants containing PDA medium for purification, identification and maintenance of culture.

\section{Pure culture of pathogen}

The purification of fungal isolation were taken following single spore isolation technique. A dilute spore suspension was poured on plain agar Petri plate to from a very thin layer on it and spores allowed to settle down on the agar surface. Settled spores were separated out from each other, selected under the microspore and encircled with the help of glass marker. They were lifted along with agar blocks and transferred to Petri plates containing sterilized PDA medium. After proper growth of fungus obtained by single spore culture regular sub-culturing was done to check contamination, till pure cultures were obtained. These cultures were sub-cultured at monthly intervals and maintained on Potato Dextrose Agar slant under refrigeration at 6 to $8{ }^{0} \mathrm{C}$ temperature for further studies.

\section{Identification of the fungus}

The pathogen was identified on the basis of the cultural and morphological characters as started below:

\section{Colony character}

The cultural and morphological characters of the fungus were recorded in Potato Dextrose Agar Medium after seven days of incubation. Colour and type of growth of the mycelium were observed.

\section{Mycelial characters}

Septation, branching pattern, colour and width of the hyphae etc. were microscopically observed and recorded.

\section{Conidial characters}

Colour, shape, size and septation of conidia were recorded under the compound microscope after 15 days of incubation. 


\section{Pathogenicity tests of A. tenuisssima}

Plant inoculation techniques (Nene et al., 1981) were carried out to determine the pathogenic capabilities of A.tenuissima from infected pigeonpea plants. The inoculum was prepared by growing pure cultures of A.tenuissima on P.D.A. medium. Healthy seeds of Alternaria blight susceptible variety Bahar were sown at rate of 15 seeds per pots. At the seedling stage, the plants were artificially inoculated by spraying inoculums (15-20 conidia/microscopic field).

Controlled plants were left, without spraying inoculum. The pots were then incubated in glass house at $28 \pm^{\circ} \mathrm{C}$ and irrigated regularly once every day to maintain sufficient moisture. The plants kept in glass house were observed critically for and blight symptoms upto 7 days of inoculation. The leaves which showed blight symptoms were considered as infected. The pathogen was reisolated from the half healthy and half infected part of leaf on Potato-Dextrose-Agar medium for confirmation of Koch's postulates.

Management of Alternaria blight disease of pigeonpea

\section{Varietal screening}

Seeds of one hundred six genotypes of pigeonpea were obtained from the Department of Genetics and Plant Breeding, N.D. University of Agriculture and Technology, Narendra Nagar (Kumarganj), Faizabad (U.P.). One hundred six genotypes were screened at Genetic and Plant Breeding Research Farm in All India Co-ordinated pigeonpea trial under artificial inoculated conditions by spraying inoculums (15-20 conidia/microscopic field).

Pigeonpea genotypes, which were screened in this experiments have been given in Table 1 .
After artificial inoculation, observations were recorded regularly upto 60 days for the appearance of Alternaria blight symptoms and severity. The disease was recorded using 1-9 scale (Anonymous, 1991) for the Alternaria blight disease of pigeonpea as described in Table 2.

\section{Statistical analysis}

The data were analysed statistically to draw the conclusion. Statistically analyses of laboratory and pot experiments were done by the method of Completely Randomized Block Design (CRD) prescribed by Goon et al., (1931).

The significance of treatments differences was tested by variance ratio test of 5 per cent level of probability.

The observation of per cent inhibition of mycelial growth, disease incidence and disease control were transferred into "Arc Sign Transformation" used for statistical analysis. Formula used for such transformed was:

\section{$=\operatorname{Sin}^{-1} \sqrt{\mathrm{P} / 100}$}

\section{Experimental Findings}

The salient findings of the present investigation are described under the following heads:

Symptomatology

Isolation, identification of the pathogen and its pathogenicity

Disease management

Identification of pigeonpea genotype(s) resistant to Alternaria tenuissima in vivo. 


\section{Symptomatology}

The sequential development of disease symptom was observed and recorded in inoculated pigeonpea plants maintained in glass house. The first symptom of disease was recorded 5 days after spraying inoculum. The Infected plants in the field showed symptoms on all the aerial parts of the plants (leaves, stem, and pods) irrespective of the age of the plant and leaves. Symptoms on leaves were small, circular, necrotic spots that develop quickly forming typical concentric rings. Later these spots coalesce and cause blighting of leaves. The leaves, stem and pod which showed blight symptoms were considered as infected (Fig. 1).

Isolation and identification of the pathogen and its pathogenicity

\section{Isolation}

Isolations were made from infected leaves. The pathogen was isolated on PotatoDextrose-Agar medium (Singh and Chaube, 1970) in Petri plate by transferring them after surface sterilization. After mycelia growth, the fungus was purified through Single spore isolation (Fig. 2). Subsequently, it was subcultured on PDA slant. The culture was maintained on PDA slant for further studies. The pathogen under study was identified as Alternaria tenuissima on the basis of its cultural and morphological characters.

\section{Identification}

Black fluffy growth of A. tenuissima was seen on PDA and the microscopic studies revealed that the mycelium was hyaline to olive - buff,

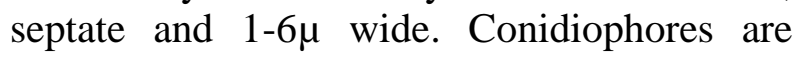
olive -buff to dark olive -buff in colour, septate, with nearly $10 \mu$ between septa, 20$100 \mu$ long, 3-4.5 $\mu$ wide, usually simple. Conidia are light brown, produced in short chains of 2-4, acrogeneous, smooth, obclavate, 30 to $40 \times 11$ to $19 \mu \mathrm{m}$ with 3 to 9 transverse and 2 to 4 longitudinal septa, smooth walled, beak 7 to $14 \times 1$ to $2 \mu \mathrm{m}$ with an obtuse end (Fig. 3).

\section{Pathogenicity}

The pathogenicity tests of Alternaria tenuissima were carried out on Alternaria blight susceptible cultivar Bahar grown in pots under glasshouse condition by inoculating plants with A. tenuissima. The first symptom of leaves started after 5 days. After 30 days of inoculation more than 90 per cent leaves of the plants were infected. The plants were normal and no blighted leaves in plants were observed in control pots. The fungus isolated from the infected plants was identified as Alternaria tenuissima based on morphological characters. Pathogenecity test were conducted to fulfill Koch's Postulates (Fig. 4 and 5).

\section{Disease management}

\section{Varietal identification of pigeonpea genotype(s) resistant to Alternaria tenuissima in vivo}

One hundred six genotypes of pigeonpea were screened at Genetics and Plant Breeding Farm for their reaction to Alternaria tenuissima under artificial inoculated conditions by spraying inoculums (15-20 conidia/ microscopic field). The genotypes were screened by following 1-9 scale.

The genotypes were grouped in various categories of resistant and susceptible on the basis of per cent blighting in infected plants as described by Nene et al., (1981) and the results are summarized in Table 3.

Out of 106 genotypes, seven genotypes viz. Path 402, Path 407,NDA14-4, NDA14-15, NDA-14-16, NDA-14-29 and NDA-14-36 
were found resistant, 33 genotypes viz., Path403, NDA-13-1, NDA-13-2, NDA7 11, NDA-3, NDA-2-SPS-1, NDA-2-SPS-2, NDA14-1, NDA-14-2, NDA 146, NDA-14-8, NDA-14-9, NDA-14-17, NDA-14-18, NDA14-19,NDA-14-23, NDA-14-24, NDA-14-26, NDA-14-27, NDA-14-28,NDA-14-30, NDA14-31, NDA-14-34,NDA-14-35,NDA-14-37, NDA14-38, NDA-GC-2010-14, NDA-GC-2, NDA-GC-2010-21， IC525505， IC2288, ICP7353, Path-14. were found moderately resistant, 53 genotypes viz., Path2, IC525446, IC 525433, IC 525500, IC525494, IC525533, Path18, Path19, Path21, Path22, Path23, Path401, Path404, Path406, Path408, Path409, Path413, Path145, NDA-2(ch), NDA-1(ch), NDA-1, NDA-94-2, NDA-14-3, NDA-14-5, NDA-14-7, NDA-14-10, NDA-14-11, NDA14-12, NDA-14-13, NDA-14-14, NDA-14-20, NDA-14-21, NDA-14-22, NDA-14-25, NDA14-32, NDA-14-33, NDA-14-39, NDAW-304, NDAW-3, Path8, Path7, Path5, Path107, Path15, Path13, NDA-GC-2010-5, NDA-GC2010-81, NDA-GC-2010-83, IC525414, IC525486, ICP-88600-2, ICP-3377, IC525425 were found moderately susceptible and 13 genotypes viz., IC525403, IC525520, Path 20, Path 24, Path 411, Path 412, NDA-12-1, NDA-GC-2010-016, NDA-GC-2010-44, Path 16, Path 10, Path 9, Path 3 were found susceptible to Alternaria blight (Table 3 and Fig. 6). The most susceptible variety Bahar showed 100 percent Blighting.

\section{Results and Discussion}

Among pulses, pigeonpea [Cajanus cajan (L.) Millsp] holds an important position, so far as its production and nutritive value concerned. Several diseases like wilt, sterility mosaic, stem rot and Alternaria blight have been reported to cause great menace for pigeonpea since long time and are considered responsible for its low yields, in spite of large acreage, next to chickpea (Grewal, 1988). Among diseases Alternaria blight caused by
Alternaria tenuissima is one of the most important and destructive disease in Uttar Pradesh and Bihar (Kushawaha et al., 2010).

Studies were carried out on the prevalence and severity of disease in central Uttar Pradesh and effect of temperature, relative humidity and rainfall on disease development. The incidence of disease varied from $18.0 \%$ to $37.5 \%$ at different locations. The temperature and humidity played the significant role in disease development while rainfall had no positive correlation with disease development. Blight symptoms on pigeonpea were observed in alarming proportion during 2009-2011 crop seasons in Andhra Pradesh state in India. The disease incidence ranged between 20-80\% irrespective of cultivars sown (Sharma et al., 2012).

Keeping in view the importance of the crop and seriousness of the disease, it was thought worthwhile to investigate the disease with objectives as outlined in the introductory chapter and the results obtained are discussed in the light of available literature as follows:

\section{Isolation and identification of the pathogen}

The pathogen was isolated from infected plant leaves on Potato-Dextrose-Agar medium. The fungus was purified through single spore isolation technique. The culture was maintained on PDA slant. The pathogen under study was identified as Alternaria tenuissima on the basis of cultural and morphological characters of the Alternaria tenuissima.

Black fluffy colony of A.tenuissima was observed on PDA and the microscopic studies revealed that the mycelium was hyaline to olive, septate and 1-6 $\mu$ wide between the septa. Conidiophores olive to dark olive, septate, with nearly $10 \mu$ between septa, 20$100 \mu$ long, 3-4.5 $\mu$ wide, usually simple. Conidia are light brown, produced in short 
chains of 2-4, acrogeneous, smooth, obclavate, 30 to $40 \times 11$ to $19 \mu \mathrm{m}$ in size with 3 to 9 transverse and 2 to 4 longitudinal septa. Beak size ranged between 7 to $14 \times 1$ to $2 \mu \mathrm{m}$ with an obtuse end. Based on the cultural and morphological characters, the pathogen was identified as Alternaria tenuissima. Similar results were reported.

Thus, the present finding of present investigation is well supported by the findings of previous workers.

\section{Symptomatology}

The sequential development of disease symptoms were observed and recorded in inoculated infected plants in glass house. During observation it was recorded that the infected plants in the field showed symptoms on all the aerial parts of the plants (leaves, stem, buds and pods) irrespective of the age of the plant and leaves. Symptoms on leaves were small, circular, necrotic spots that develop quickly forming typical concentric rings. Later these spots coalesce and cause blighting of leaves. The spots were initially light brown and later turned dark brown.

On stems, spots were sunken with concentric rings. In severe infection, defoliation and drying of infected leaves, branches and flower buds were observed. The fungus isolated from the infected plants was identified as Alternaria tenuissima based on morphological characters. Pathogenecity test were conducted to fulfill Koch's Postulates. Similar results were reported by Sharma et al., (2012). These are in agreement with the present findings.

\section{Pathogenicity test}

The pathogenicity study revealed that spots on leaves appears after 5 days of inoculation. The Infected plants in the field showed symptoms on leaves, stem and pods were small, circular, necrotic spots that developed quickly forming typical concentric rings.

Later, these spots coalesced and caused blighting of leaves. Spots were also recorded in artificially inoculated plants as light brown which later turned dark brown in colour. No symptoms were observed on control plants. The similar results were also reported by Kannaiyan and Nene in 1977.

\section{Disease management}

\section{Host resistance}

The search for source of donors with a high degree of resistance for use as parental material in breeding programmes for Alternaria tenuissima has always been desirable. There is no doubt about the fact that the use of resistant variety is one of the best methods of disease management. Therefore, studies were planned to search out the genotypes against Alternaria tenuissima under artificial inoculated conditions by spraying inoculums (15-20 conidia/microscopic field). The genotypes were screened by following 1-9 scale.

Out of 106 genotypes, seven genotypes viz. Path 402, Path 407, NDA14-4, NDA14-15, NDA-14-16, NDA-14-29 and NDA-14-36 were found resistant, 33 moderately resistant, 53 moderately susceptible and 13 were susceptible to Alternaria tenuissima. The most susceptible variety Bahar showed 100 percent disease.

Kumar and Rani (2010) screened 96 genotypes of pigeonpea in field under artificially inoculated conditions. Among them 3 genotypes viz., RAUP-32, RAUP-34 and Pusa-(B)-35 were resistant, 12 were moderately resistant, 37 were moderately susceptible and 33 were susceptible to the Alternaria disease. 
Table.1 List of pigeonpea genotypes used for screening

Name of genotypes

NDAW304， NDA W3， NDAGC2010-5， NDAGC2010-016， NDAGC2010-14， NDAGC2010-2, NDAGC2010-81， NDAGC2010-21， NDAGC2010-83， NDAGC2010-44， IC525505， IC2288, IC525414, IC525486, ICP7353, ICP88600-2, IC525494, IC 525425, Path 107, Path16, Path15, Path14, Path13, Path10, Path9, Path8, Path7, Path5, Path3, Path2, ICP3377, IC525446, IC525403, IC525433, IC525500, IC525494, IC525520, IC525533,Path18, Path19, Path20, Path21, Path22, Path23, Path24, Path401, Path402, Path403, Path404, Path406, Path407, Path408, Path409, Path411, Path412, Path413, Path145, NDA-13-1, NDA-13-2, NDA-2(ch), NDA-1(ch), NDA-12-1, NDA-7-11, NDA-1201, NDA-3, NDA-2 SPS2, NDA-2 SPS1, NDA-1, NDA-94-2, NDA-14-1, NDA-142, NDA-14-3, NDA-14-4, NDA-14-5, NDA-14-6, NDA-14-7, NDA-14-8, NDA-14-9, NDA14-10, NDA14-11, NDA-14-12, NDA-14-13, NDA-14-14, NDA-14-15, NDA-14-16, NDA-14-17, NDA-14-18, NDA-14-19, NDA-14-20, NDA-14-21, NDA-14-22, NDA-14-23, NDA-14-24, NDA-14-25, NDA-14-26, NDA-14-27, NDA-14-28, NDA-14-29, NDA-14-30, NDA-14-31, NDA-14-31, NDA-14-32, NDA-14-33, NDA-14-34, NDA-14-35, NDA-14-36, NDA-14-37, NDA-14-38, NDA-14-39.

Table.2 Disease rating scale for Alternaria blight (Anonymous, 1991)

\begin{tabular}{c|c|l|l} 
S. No. & Scale & \multicolumn{1}{|c|}{$\%$ leaves Infection } & \multicolumn{1}{c}{ Disease reaction } \\
\hline 1. & 1 & No symptoms on any plant & Disease free \\
2. & 2 & $0.1-5 \%$ & Resistant \\
3. & 3 & $5.1-10 \%$ & Resistant \\
4. & 4 & $10.1-20 \%$ & Moderately Resistant \\
5. & 5 & $20.1-30 \%$ & Moderately Resistant \\
6. & 6 & $30.1-40 \%$ & Moderately Susceptible \\
7. & 7 & $40.1-50 \%$ & Moderately Susceptible \\
8. & 8 & $50.1-75 \%$ & Susceptible \\
9. & 9 & Above $75 \%$ & Susceptible \\
\hline
\end{tabular}

Table.3 Performance of pigeonpea genotypes against Alternaria tenuissima in vivo

\begin{tabular}{|c|c|c|}
\hline S. No. & Reaction & Name of the genotypes \\
\hline 1. & Resistant & Path 402, Path 407, NDA-14-4, NDA-14-15, NDA-14-16, NDA-14-29, NDA-14-36 \\
\hline 2. & $\begin{array}{l}\text { Moderately } \\
\text { resistant }\end{array}$ & $\begin{array}{l}\text { Path403,NDA-13-1, NDA-13-2, NDA-7-11, NDA-3, NDA-2-SPS-1, NDA-2-SPS-2, } \\
\text { NDA-14-1, NDA-14-2, NDA-14-6, NDA-14-8, NDA-14-9, NDA-14-17, NDA-14-18, } \\
\text { NDA-14-19, NDA-14-23, NDA-14-24, NDA-14-26, NDA-14-27, NDA-14-28, NDA- } \\
\text { 14-30, NDA-14-31, NDA-14-34,NDA-14-35,NDA-14-37,NDA-14-38, NDA-GC- } \\
\text { 2010-14, NDA-GC-2, NDA-GC-2010-21, IC-525505, IC2288, ICP7353, Path-14 }\end{array}$ \\
\hline 3. & $\begin{array}{l}\text { Moderately } \\
\text { Susceptible }\end{array}$ & $\begin{array}{l}\text { Path2, IC525446, IC 525433, IC 525500, IC525494, IC525533, Path18, Path19, } \\
\text { Path21, Path22, Path23, Path401, Path404, Path406, Path408, Path409, Path413, } \\
\text { Path145, NDA-2(ch), NDA-1(ch), NDA-1, NDA-94-2, NDA-14-3, NDA-14-5, NDA- } \\
\text { 14-7, NDA-14-10, NDA-14-11, NDA-14-12, NDA-14-13, NDA-14-14, NDA-14-20, } \\
\text { NDA-14-21, NDA-14-22, NDA-14-25, NDA-14-32, NDA-14-33, NDA-14-39, } \\
\text { NDAW-304, NDAW-3, Path8, Path7, Path5, Path107, Path15, Path13, NDA-GC- } \\
\text { 2010-5, NDA-GC-2010-81, NDA-GC-2010-83, IC525414, IC525486, ICP-88600-2, } \\
\text { ICP-3377, IC525425. }\end{array}$ \\
\hline 4. & Susceptible & $\begin{array}{l}\text { IC525403, IC525520, Path 20, Path 24, Path 411, Path 412, NDA-12-1, NDA-GC- } \\
\text { 2010-016, NDA-GC-2010-44, Path 16, Path 10, Path 9, Path } 3 .\end{array}$ \\
\hline
\end{tabular}


Fig.1 Pigeonpea plant showing typical symptom of alternaria blight

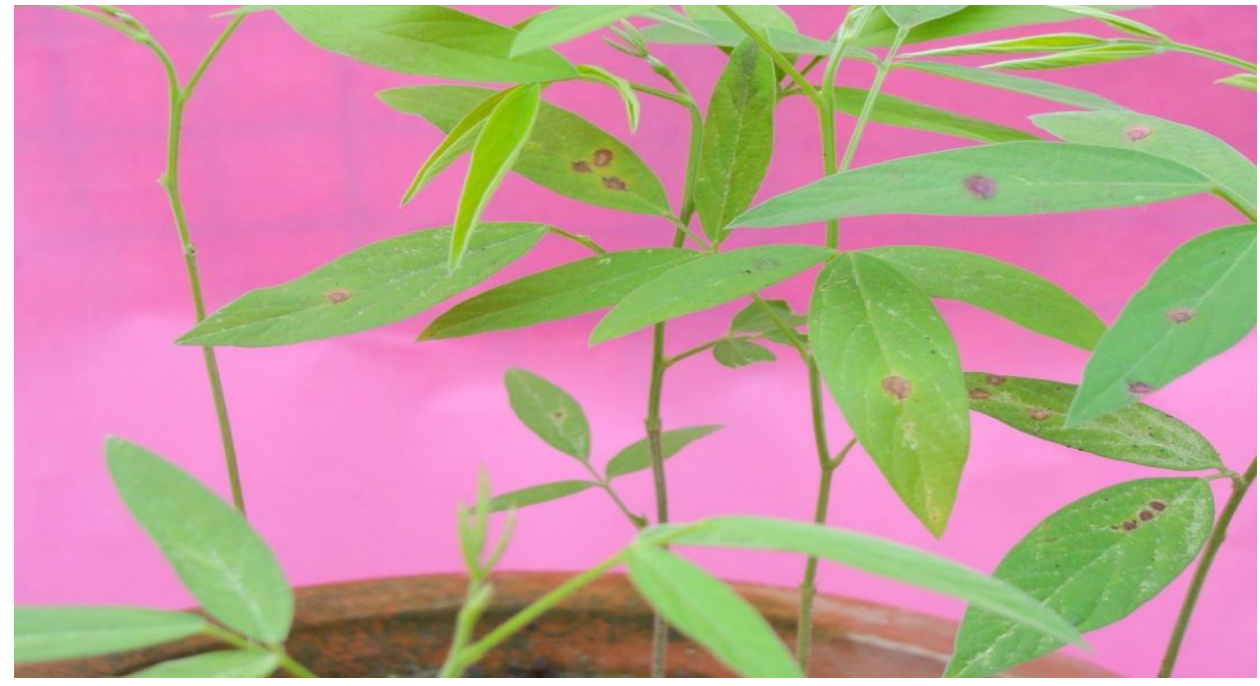

Fig.2 Pure culture of Alternaria tenuissima

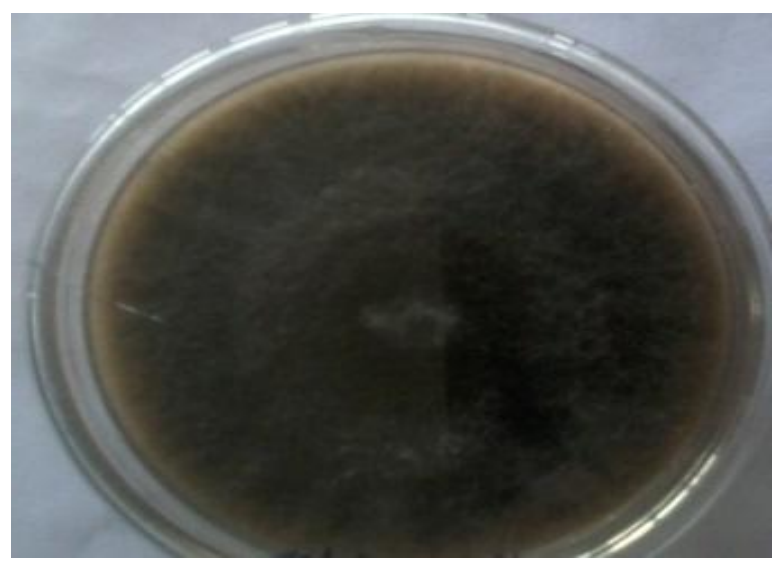

Fig.3 Conidia with conidiophores of Alternaria tenuissima

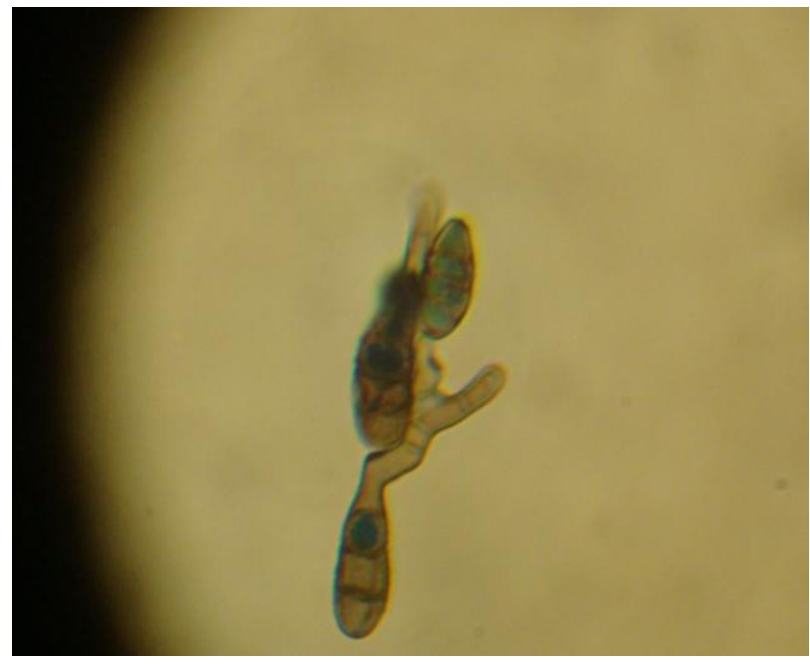


Fig.4 Healthy pigeonpea plant

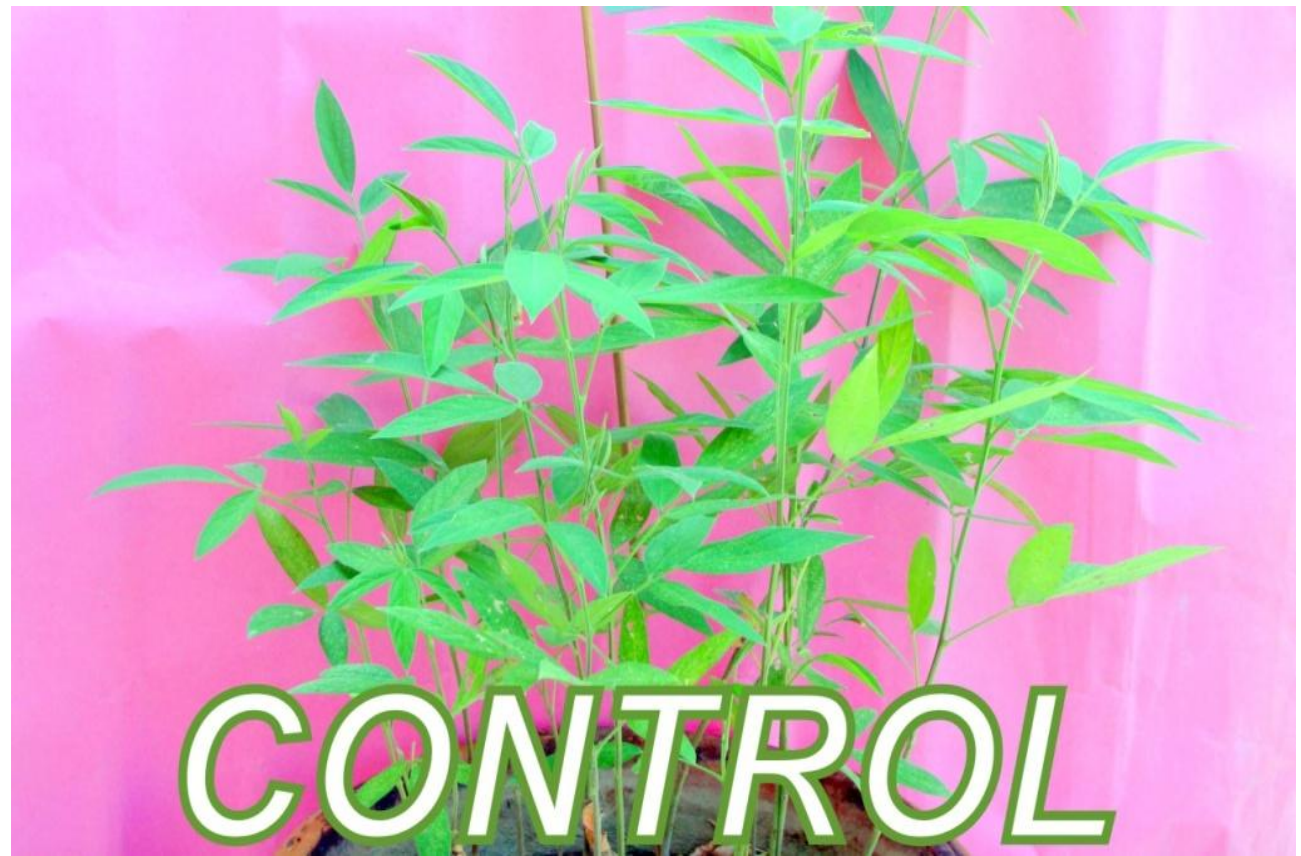

Fig.5 Alternaria blight incidence in A.tenuissima infected plants

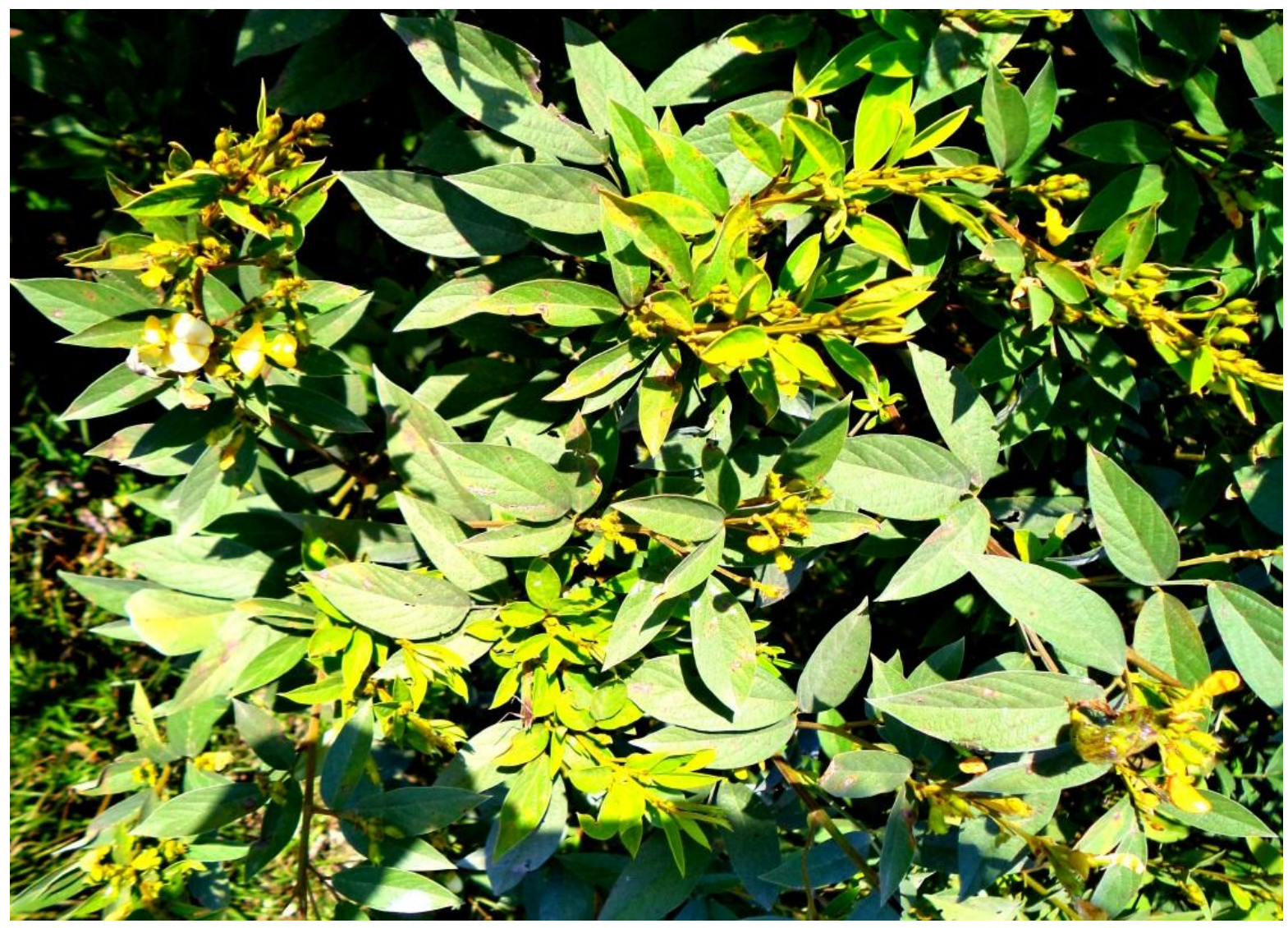


Fig.6 Varietal screening against Alternaria blight

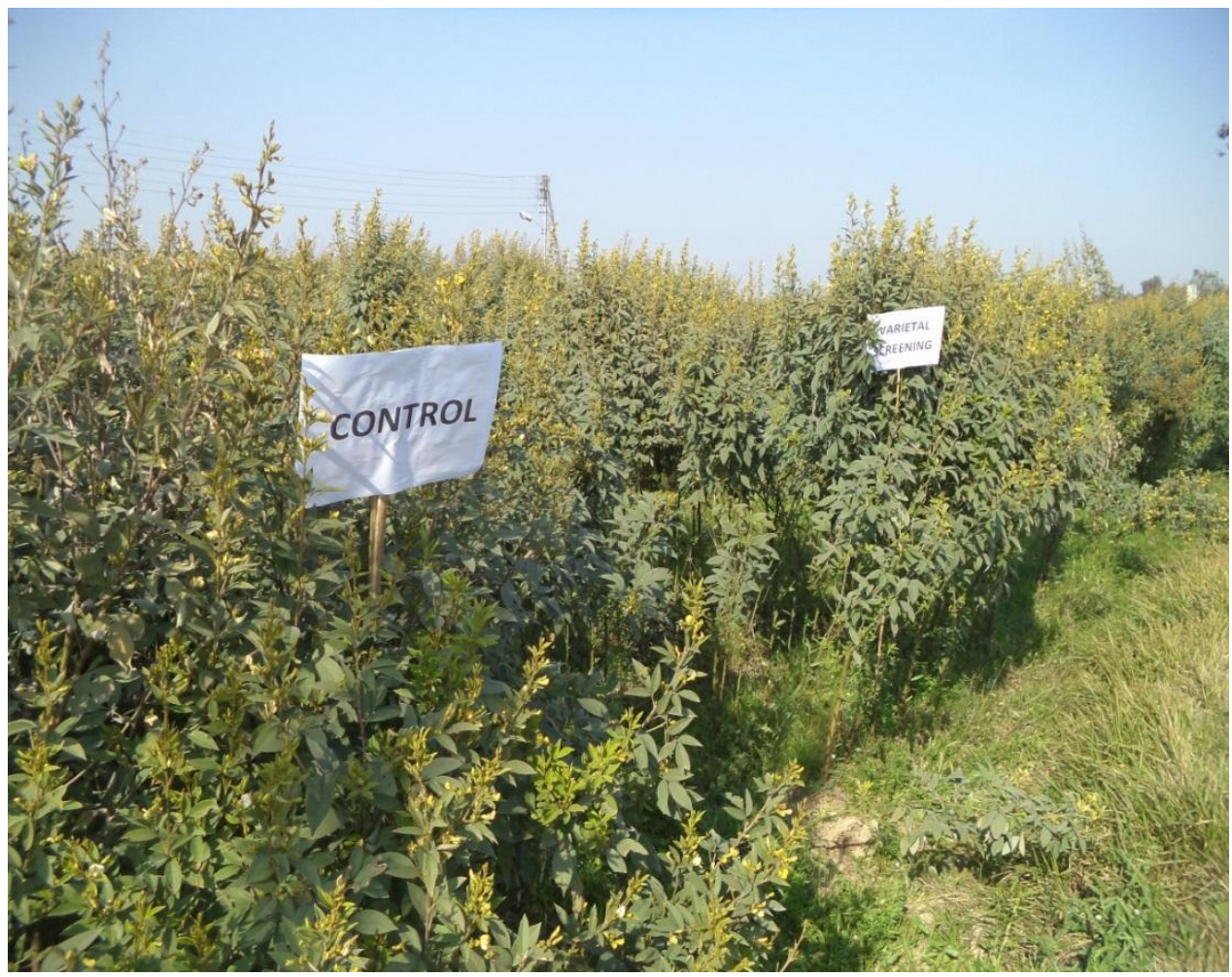

Venkateswarlu (1981) reported four pigeonpea genotypes, MA-128-1, MA-128-2, DA-2 and 20(105) resistant to Alternaria blight under natural field condition were also reported resistant under artificially inoculated condition in green house (Kannaiyyan and Nene, 1986.).

Pigeonpea [Cajanus cajan (L.) Millsp.] is an important Kharif pulse crop grown throughout India. pigeonpea play very important role in the supply of the protein to under nourished vegetarian population of the country. It suffers from a number of diseases. Alternaria blight caused by Alternaria tenuissima is one of the most widespread and destructive foliar diseases of Pre-Rabi pigeonpea. Use of synthetic fungicides has led to the emergence of several problems like environment pollution, residual effect in grain and killing of non-target organism(s). Hence, for minimizing the losses caused by wilt, this disease needs inexpensive and environmentally safe management practices. Many plant extracts are known for their antifungal activity.

Different aspects of disease as well as pathogen were studied with symptomatology and disease management through host resistance and use of plant extracts against $A$. tenuissima.

The salient finding of studies are summarized below:

Alternaria tenuissima was isolated from the infected leaves of the plant. The morphological characters of the fungus were studied after isolating the fungus on PotatoDextrose-Agar medium. The mycelium was

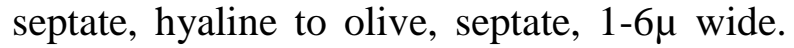
Conidiophores are olive -buff to dark olive, septate, with nearly $10 \mu$ between septa, 20$100 \mu$ long, 3-4.5 $\mu$ wide, usually simple. The fungus produced conidia which were light 
brown, produced in short chains of 2-4, acrogeneous, smooth, obclavate, 30 to $40 \times 11$ to $19 \mu \mathrm{m}$ with 3 to 9 transverse and 2 to 4 longitudinal septa, smooth walled, beak 7 to $14 \times 1$ to $2 \mu \mathrm{m}$ with an obtuse end.

The first appearance of Alternaria blight symptoms was noticed 5 days after artificial inoculation on plants in the glass house. The Infected plants in the field showed symptoms on all the aerial parts of the plants (leaves, stem, buds and pods) irrespective of the age of the plant and leaves. Symptoms on leaves were small, circular, necrotic spots that develop quickly forming typical concentric rings. Later these spots coalesce and cause blighting of leaves. The leaves which showed blight symptoms were considered as infected.

The pathogenicity of $A$. tenuissima was proved following the Koch's postulates.

One hundred six genotypes of pigeonpea were screened against $A$. tenuissima. The genotypes were grouped in various categories of resistant and susceptible on the basis of percent blighting in infected plants under artificial inoculated conditions by spraying inoculums (15-20 conidia/microscopic field). The genotypes were screened by following 19 scale.

Out of 106 genotypes, 7 genotypes viz., NDA 402, NDA 407, NDA-14-4, NDA-14-15, NDA-14-16, NDA-14-29 and NDA-14-36 were resistant and 33, 53 and 13 were moderately resistant, moderately susceptible and susceptible, respectively to Alternaria blight disease whereas Bahar showed highly susceptible reaction against this disease.

\section{Acknowledgment}

We are highly grateful and feel proud privilege to take an opportunity of expressing our deep and heartiest sense of gratitude to
Dr. S.K. Singh, Assistant Professor, Department of Plant Pathology and Chairman of my Advisory Committee for his scholarly advice, during whole period of this study. The study was self-funded. We also declare for no conflict of interest from any of the authors.

\section{References}

Ali, M. (2007). Global pulse production trends and challenges. National symposium on legumes for ecological sustainability: emerging challenges and opportunities. IIPR-Kanpur: 7-10

Anonymous (1991). Annual Report on Pigeonpea. All India Co-ordinated Research Project on Pigeonpea, IIPR, Kanpur. Pp., 240.

Anonymous (2013).Project Coordinated Report, 2012-13. All India Co-ordinated Research Project on Pigeonpea, IIPR, Kanpur. p.p., 16

Goon, A.M., Gupta, M.K. and Das Gupta, B. (1931). Fundamental of Statistics, Vol.2 published by Bhattacharjee for the world press Pvt. Ltd. 37 A College Street, Calicut-700073, pp.145.

Grewal, J.S. (1988). Disease of pulse cropsAn overview. Indian Phytopath 41(2): $1-14$.

Kannaiyan, J. and Nene, Y.L. (1977) Control of seed borne Alternaria tenuissima in pigeonpea. Tropical Grain Legume Bulletin No.9.

Kannaiyan, J., and Nene, Y.L. (1986). Screening Pigeonpea for resistance to Alternaria Blight. Indian Phytopath. 39(4):547-549.

Kumar, S. and Rani, A. (2010). Resistance in pigeonpea to Alternaria blight. Ann.Pl.Prot.Sci. 18(2):548-549.

Kushwaha, A., Nigam, R, and Srivastava, A. (2010 a). Occurrence and severity of Alternaria blight of pigeonpea in central U.P. Int. Jr. Pl. Prot. 3(2):361. 
Kushwaha, A., Srivastava, A., Nigam, R. and Srivastava, N. (2010 b). Management of alternaria blight of pigeonpea crop through chemicals. Int. Jr. Pl. Prot. 3(2): 313-315.

Mehta, P.P. and Sinha, R.K.P. (1982). A new leaf spot disease of arhar from India.Sci \& cult. $48(2): 44$.

Narula, P.N. (1983). Short-duration pigeonpeas escape leaf blight disease in late seedling in Bihar. Int. Pigeonpea Newsletter 2(2):50-51.

Nene, Y.L., Sheela, V.K. and Sharma, S.B. (1996). A world list of chickpea and pigeonpea pathogens. $5^{\text {th }}$ edn.
Patancheru 502324, Andhra Pradesh, India: International Crops Research Institute for the Semi-Arid Tropics (Semi-formal Publication), Hyderabad.

Sharma, M., Ghosh, R., Mangala, U.N., Saxena, K.B. and Pande, S. (2012) Alternaria tenuissima causing alternaria blight on pigeonpea [Cajanus cajan (L.) Millsp.] in India. Plant Disease, 96(2). 152-158.

Venkateswarlu, S., Reddy, A.R., Singh, O.N. and Chauhan, V.B. (1981). Alternaria blight: The most serious disease of post rainy season (Rabi) pigeonpea. Int. Pigeonpea Newsletter 1:28-29.

\section{How to cite this article:}

Utkarsh Singh Rathore, S.K. Singh and Sandeep Kumar. 2018. Identification of Resistant Sources for Alternaria Blight of Pigeonpea (Cajanus cajan L. Millsp). Int.J.Curr.Microbiol.App.Sci. 7(04): 3380-3393. doi: https://doi.org/10.20546/ijcmas.2018.704.382 